\title{
NeOliberalismo E Lutas Sociais: A EMERGÊNCIA DOS MOVIMENTOS PIQUETEROS E ALTERMUNDIALISTAS NO CONTEXTO NEOLIBERAL ${ }^{1}$
}

\section{Elaine Regina Aguiar Amorime Santiane Arias $^{2}$}

\begin{abstract}
Resumo
A introdução das políticas neoliberais teve impactos sobre os movimentos sociais, atingindo sua capacidade organizativa e de resistência. Porém, a partir de meados da década de 1990 difundiram-se várias mobilizações de oposição ao neoliberalismo, entre as quais, destaca-se a emergência de dois movimentos sociais - os piqueteros e os altermundialistas. Com base nas pesquisas que estamos desenvolvendo, este artigo discute o surgimento e a composição social de cada um deles, além dos elementos que os particularizam enquanto movimentos que se constituíram como resultado e reação ao neoliberalismo.
\end{abstract}

Palavras-chave: Neoliberalismo. Lutas sociais. Movimento altermundialista. Movimentos piqueteros.

\footnotetext{
${ }^{1}$ Este texto é uma versão modificada do trabalho que apresentamos no "Congresso Karl Marx", em novembro de 2008, na Universidade Nova de Lisboa, Portugal.

${ }^{2}$ Doutorandas em Ciência Política pelo Instituto de Filosofia e Ciências Humanas da Universidade Estadual de Campinas. End. eletrônicos: amorim_elaine@ig.com.br; santiane@gmail.com
} 


\title{
Neoliberalism and Social Struggles: the emergence of Piqueteros and anti-globalization movements in the NEOLIBERAL CONTEXT
}

\begin{abstract}
The introduction of neoliberal policies had impacts on social movements, undermining their organizational capacity and resistance. However, since the mid1990s a number of instances of mobilization against neoliberalism have emerged, among which we highlight two: the piqueteros (movements of the unemployed in Argentina) and the anti-globalization movement. Based on the research we are developing, this article discusses the emergence and the social composition of each, as well as the elements that distinguish them as movements that were formed as a result of, and in reaction to, neoliberalism.
\end{abstract}

Keywords: Neoliberalism. Social struggles. Anti-globalization movement. Movements of the unemployed in Argentina (piqueteros).

\section{INTRODUÇÃO}

0 s últimos trinta anos do século vinte trouxeram consigo mudanças significativas e de grande impacto para as sociedades capitalistas. Nesse sentido: transformações tecnológicas importantes permitiram alterações na concepção de espaço e tempo, fator decisivo na extração de capital; uma reestruturação da produção, incorporando inovações não apenas tecnológicas, mas organizacionais incidiram diretamente sobre o modo de vida do trabalhador. Acrescentemos aos itens já indicados o fim do chamado "socialismo real" sob a influência político-ideológica da extinta União Soviética e teremos um cenário com elementos e rearranjos consideravelmente novos que tiveram consequências para o sistema político e, particularmente, para a ação coletiva das sociedades contemporâneas.

Entre o colapso da experiência socialista soviética e a consolidação da ideologia e da política econômica neoliberal assiste-se um forte recuo das forças que, ao menos até então, compunham o campo hegemônico dentro da esquerda. Um recuo que, em nossa opinião, não ocorreu como consequência direta das transformações tecnológicas, tal como foi interpretado por parte considerável da 
literatura sobre as sociedades contemporâneas ${ }^{3}$. Esse processo contou com o uso de força política e militar e, arriscamos dizer aqui, jamais se assentou de forma tão confortável que pudesse prescindir totalmente dela.

Para compreender o quadro que aqui traçamos faz-se necessário antes uma advertência. As mudanças acima brevemente pontuadas não são por nós apreendidas como "frutos naturais" do desenvolvimento tecnológico, mas, ao contrário, encontram-se profundamente associadas à lógica do desenvolvimento da sociedade capitalista como um todo, e, portanto, aos processos políticos que lhe são próprios.

0 processo de implantação do modelo político-econômico neoliberal, apesar das diferenças, sobretudo regionais, colocou em curso medidas que viabilizaram, em geral: queda salarial, desregulamentação das leis trabalhistas, precarização das condições de trabalho e aumento do desemprego. Medidas que, via de regra, vieram acompanhadas de um discurso de legitimidade pautado na oposição às experiências sócio-históricas de regulação e planejamento econômico, tais como o Estado de Bem-Estar e o "socialismo real". Este discurso denunciava a inoperância da intervenção estatal, bem como o caráter "utópico" e "ideológico" dos projetos de construção de uma sociedade não capitalista .

É nesse sentido que consideramos o processo de implantação do neoliberalismo fundamental para a análise da ação coletiva dos dias que se seguem. De acordo com Gerard Duménil e Domique Lévy (2006, 2004), a partir de meados dos anos de 1970 tem-se o início de um processo de re-configuração da luta de classes, no qual uma fração das classes dominantes (a qual os autores denominaram "finanças") exerce franca hegemonia. 0 neoliberalismo definiria uma nova fase do capitalismo cujo objetivo principal é a restauração do poder

\footnotetext{
${ }^{3}$ Para uma análise crítica do determinismo tecnológico presente na literatura do período, particularmente daquela referente à sociologia do trabalho, ver Amorim (2006).

${ }^{4}$ Assim, de acordo com Moraes (2001), o neoliberalismo consolidou-se por um constante ataque às formas de regulação econômica do século XX - tais como: o socialismo, o keynesianismo, o Estado do Bem-Estar, o terceiro-mundismo e o desenvolvimentismo latino-americano. Do mesmo modo, para Anderson (1995), o neoliberalismo se diferenciou do liberalismo clássico fundamentalmente pelo contexto em que surgiu, compondo uma intervenção teórica e política contra o Estado interventor e de Bem-Estar. A crítica a papel do Estado, apresentado de forma abstrata e geral, não corresponde, no entanto, à prática política neoliberal. Para Boito Jr. (1999, p. 23), existe "uma contradição entre os princípios doutrinários gerais, que dominam a superfície do seu discurso e que estão concentrados na apologia do mercado, e suas propostas de ação prática, que não dispensam a intervenção do Estado e preservam os monopólios".
} 
político e econômico das frações superiores da classe capitalista. Um poder que teria sido abalado após a Segunda Guerra Mundial, mas progressivamente resgatado a partir da década de 1980.

Entre as principais medidas econômicas adotadas para alcançar tal intento contam-se: a abertura dos mercados, a privatização das empresas estatais, inclusive dos serviços sociais, a luta prioritária contra a inflação, a desregulamentação do mercado financeiro e do trabalho. Nesse sentido, as medidas acima pontuadas expressariam o avanço dessa fração, as finanças, ante as demais. É esse rearranjo nas relações de classes que marca a nova ordem social instaurada com 0 neoliberalismo. Destacamos, no entanto, a não uniformidade desse processo. Este variou em intensidades e consequências de região para região e de país para país, de acordo com a posição ocupada no quadro de forças imperialistas (centro/ periferia), e de acordo com as lutas travadas no interior de cada formação social. É interessante notar que essas diferenças têm implicações, não apenas no âmbito das classes dominantes, mas no perfil da resistência das classes dominadas. Por exemplo, enquanto na Europa, dentre os altermundialistas destaca-se a ação da ATTAC, na América Latina é digno de nota o papel da Via Campesina, além do exemplo dos piqueteros na Argentina. Lutas sociais que evidenciam processos específicos de implantação do neoliberalismo.

Se na Europa, o avanço do capitalismo neoliberal atingiu o "compromisso keynesiano" e o Estado de Bem-Estar Social, na América Latina ele alterou 0 quadro político e econômico, afetando as relações de classes nessa região, mas igualmente as relações com os países capitalistas centrais. 0 significativo processo de industrialização das principais economias latino-americanas e a expansão de direitos sociais e trabalhistas verificados no pós-guerra reverteram-se a partir da década de 1970.

As privatizações de empresas públicas, particularmente do setor de serviços, e com elas todo um processo de terceirização e de redução de trabalhadores, bem como as mudanças organizacionais implantadas nas empresas atingiram a classe trabalhadora como um todo. A transferência da instabilidade do mundo financeiro para dentro das fábricas atingiu de modo violento o operariado, mas não deixou incólumes os assalariados de alta posição. Entre algumas das consequências constatadas observam-se a redefinição na estrutura hierárquica das empresas, salários associados à produtividade e alta concorrência do mercado de trabalho, com exigências cada vez maiores de qualificação. 
Altos índices de desemprego afetando diversas camadas sociais; feminização do trabalho associada a baixos salários; jovens diplomados sujeitos a trabalhos instáveis; privatização de vastos setores da economia provocando, além de desemprego, queda da qualidade dos serviços prestados; extensão da lógica do mercado para áreas ainda preservadas, como o caso da privatização de terras até então de uso coletivo, da educação e da saúde; cortes de direitos sociais adquiridos; endurecimento das leis de imigração... A lista de áreas e grupos afetados negativamente pela implantação da receita neoliberal é extensa.

É neste contexto que logo a partir da segunda metade dos anos 1990 emergem em diferentes regiões do globo manifestações de oposição às políticas neoliberais. Dentre estas manifestações discutiremos aqui dois movimentos: 0 altermundialismo, centrando nossa análise na ATTAC, uma de suas organizações mais representativas, e os piqueteros, como são denominados os movimentos de trabalhadores desempregados da Argentina. Podemos apontar alguns elementos específicos da ATTAC e dos piqueteros para justificar a nossa escolha:

I) a ATTAC participou da fundação do Fórum Social Mundial - considerado o momento e o espaço de convergência do altermundialismo - e é, ainda hoje, membro do seu Conselho Internacional, considerado órgão máximo no processo de organização do evento e responsável por sua Carta de Princípios; ademais ela surgiu praticamente junto à noção de altermundialismo, ao contrário de outros movimentos com uma história muito anterior, facilitando assim a análise da sua especificidade;

II) os piqueteros por terem se constituído como um dos exemplos mais significativos do que pode ser considerado um movimento social de desempregados, cujas ações tiveram impactos políticos de grande envergadura na Argentina, como se verificou em 2001, momento ápice da crise instalada no país após a aplicação das reformas neoliberais; além disso, pela trajetória dos piqueteros, a qual, ainda que marcada por recuos, conseguiu se inscrever no plano das ações coletivas por meio da sua capacidade de organização.

De um modo geral, a ATTAC e os movimentos piqueteros representam formas de lutas que emergem em um mesmo período, quando os impactos sociais e econômicos produzidos pelo neoliberalismo não deixavam dúvidas da necessidade da conformaçã̃o de uma nova correlação de forças que fosse capaz de frear as políticas neoliberais. Por isso, nosso objetivo neste artigo é discutir, com base nas pesquisas que estamos desenvolvendo sobre esses movimentos, o 
surgimento e a composição social de cada um deles, além dos elementos que os particularizam enquanto movimentos que se constituíram como resultado e reação ao neoliberalismo, aplicado tanto no centro como na periferia do capitalismo.

\section{O MOVIMENTO ALTERMUNDIALISTA}

Segundo José Corrêa Leite (2005), os anos 1990 colocam em cena novas resistências. Movimentos que apesar da ligação com os movimentos sociais das décadas de 1970/1980 se diferenciariam dessas experiências por conta do seu "caráter político inovador", isto é, global, mas não hierárquico. Para o autor, o que subsistiu de correntes anticapitalistas conhece, através das transformações do capitalismo e da experiência política desse período recente, uma mudança profunda "com a convergência de muitos movimentos de caráter anti-sistêmico em um movimento novo, global, de oposição ao neoliberalismo, à dominação imperial e à militarização" (LEITE, 2005, p. 337).

Esse novo movimento analisado por Leite (2005) é conhecido como altermundialismo. 0 movimento altermundialista surge oficialmente em 1999, em Seattle nos Estados Unidos, por ocasião do encontro da Organização Mundial do Comércio (OMC). As manifestações que ocorreram durante todos os dias de reunião agregaram algo em torno de 50 mil manifestantes. As manifestações contra as organizações multilaterais, no entanto, não começaram e nem terminaram em Seattle. Em maio de 1998, mais de 70.000 pessoas reuniram-se na Inglaterra durante a reunião do G-8. No ano seguinte os encontros ocorreram na Alemanha, Holanda, Mônaco, Itália e em 2000 a marcha foi à Suíça, Tailândia, Argentina, Japão, Austrália, República Tcheca, Coréia e França (EVANGELISTA, 2001). Apesar disso, Seattle é considerada um marco. Primeiro porque representou uma importante vitória do movimento - a reunião foi suspensa, o Acordo Multilateral Internacional (AMI) vetado e a abertura de uma nova rodada de negociações adiada; segundo porque explicitou aos militantes a inviabilidade de avanços através do diálogo com o Fundo Monetário Internacional (FMI) e o Banco Mundial (BM).

Entre os diversos movimentos, organizações e redes presentes no altermundialismo encontram-se: a Confederação Camponesa, liderada por Jose Bové; ONGs ambientalistas, como o Greenpeace e a Friends of the Earth; centros virtuais de mobilização como a Direct Action Network (DAN) e a Ação Global dos Povos; os militantes Tute Biache e Desubbedienti; o Movimento de 
Resistência Global, criado na Espanha, a princípio, em apoio aos zapatistas; a Via Campesina, criada em 1993 com sede em Honduras, e que aglutina movimentos rurais da América Latina, África e Ásia; a Assembléia dos Pobres, fundada em 1995 na Tailândia, composta de pequenos camponeses e por trabalhadores rurais que perderam suas terras depois da construção de barragens; o MST, no Brasil, um dos pilares da Via Campesina; as Marchas Européias contra o Desemprego, a Precariedade e as Exclusões, iniciadas em 1995 na França; a Marcha Mundial das Mulheres, que saiu do Canadá para outros países sob o lema: "a globalização tem sexo!"; os centros de pesquisas como a: Focus on the Global South, a CLACSO (Centro Latinoamericano de Ciências Sociais) e o Fórum de Alternativas; os centros de informação como: a ALAI (Agencia Latinoamericana de Información) e o CMI (Centro de Mídia Independente); as centrais de trabalhadores como: a CTA (Central dos Trabalhadores Argentinos) e a CES (Confederação Européia de Sindicatos); ONGs como: a Public Citizen, a 50 years is enough!, a ABONG (Associação Brasileira de ONGs); os cristãos da rede Lilliput; o movimento $\mathrm{Ya}$ Basta ...

0 nível real de integração entre essas organizações é digno de questionamento, e em que medida podemos falar de um movimento altermundialista é algo para uma discussão próxima. Ressalvas feitas, as manifestações e os fóruns sociais (locais, regionais e mundiais) atestam certo grau de convergência. A diversidade de organizações, nacionalidades e demandas, no entanto, não impede uma relativa homogeneidade social, tampouco o consenso em torno da inviabilidade da "mundialização neoliberal".

Algumas enquetes realizadas com militantes altermundialistas apontam para uma forte presença de um grupo tradicionalmente associado às classes médias. Nos Fóruns Sociais Mundiais, por exemplo, de um modo geral vem se destacando a presença de jovens universitários e profissionais de 0NGs. Dados apresentados pelo IBASE (2006, p.1) sobre a 6a edição do fórum indicam que na Venezuela 79\% estavam cursando ou haviam feito um curso universitário e 72\% na Índia, sendo que $1 / 4$ dos participantes na África tinha mestrado e doutorado 5 . Os dados da $3^{a}$ edição apresentavam o mesmo perfil. Segundo Boaventura de Souza Santos (2005, p. 67), o nível de estudo dos participantes é bem elevado: 73\% dos participantes possuem grau acadêmico, completo ou incompleto; 9\%

${ }^{5} 0$ Fórum Social Mundial de 2006 foi descentralizado, ocorrendo na Ásia, África e América Latina. 
têm mestrado ou doutorado, porcentagem que aumenta para 17\% no caso dos delegados, atingindo $30 \%$ entre os delegados brasileiros.

Sobre o perfil ocupacional dos altermundialistas, os dados de 2003, na terceira edição do Fórum, apontam que 43\% trabalham para instituições ou 0NGs, 36\% são de funcionários públicos, apenas 4\% trabalham na indústria, 3\% na agricultura e 12\% no comércio. 0 setor de serviços é o mais representado, preenche 79\% das ocupações dos participantes que têm emprego.

Dentre o movimento altermundialista, o caso da ATTAC (Associação pela Tributação das Transações Financeiras para a Ajuda dos Cidadãos) é bastante ilustrativo. Considerada uma das principais idealizadoras do Fórum Social Mundial, a associação nasceu em 1998, na França, e coordena uma das principais campanhas altermundiais, qual seja, a tributação do capital financeiro através da aplicação da taxa Tobin ${ }^{6}$; proposta que se tornou símbolo altermundialista e uma das principais bandeiras nas marchas contra o Banco Mundial, a OMC e 0 FMI.

Em sua pesquisa de doutorado, Elise Cruzel (2006), partindo de uma sociologia do engajamento, analisa a trajetória militante dos attacantes (Comitês de Gironde e de Haute-Garonne), identificando pontos comuns, como, por exemplo, uma "carreira militante humanitária" - fruto de experiências comunitárias, sobretudo, religiosas. De acordo com a autora, as entrevistas realizadas evidenciaram impressionantes regularidades biográficas que poderiam iluminar a forma do engajamento do movimento altermundialista. Existe, no entanto, outra regularidade que não pode passar despercebida na nossa análise, a saber, a ocupação dos entrevistados. Entre os citados: engenheiros, gestores de empresa, assistentes sociais, desenhistas gráfico, professores e bibliotecários.

De acordo com a história oficial da associação, o seu projeto nasceu de um editorial escrito por Ignácio Ramonet, em dezembro de 1997, no jornal Le Monde Diplomatique. No final desse artigo, Ramonet conclui: por que não criar, em escala planetária, uma organização não governamental em defesa de uma taxa Tobin com o objetivo de ajudar os cidadãos? Essa pergunta simples recebeu

\footnotetext{
${ }^{6}$ A taxa Tobin é uma tributação entre 1\% e 0,25\% sobre as transações financeiras. Essa proposta foi elaborada em 1978 pelo economista James Tobin - prêmio Nobel em 1981. Seu principal objetivo era limitar os riscos de especulação gerados pelo fim da conversibilidade entre o dólar e o ouro. Mas o projeto só veio a ganhar notoriedade quase vinte anos depois, em 1998 com a ATTAC (CHESNAIS, 1999).
} 
na época milhares de respostas de indivíduos, associações, sindicatos e jornais. Esse debate caiu em solo tão fértil, que já em março de 1998 aconteceu o primeiro encontro entre os grupos interessados para a discussão dos pontos essenciais da associação.

Em apenas um ano, 10 mil adesões. Mas foi após a manifestação de Gênova, em 2001, organizada por ocasião do encontro do G8, e na qual se reuniram em torno de 200 mil pessoas, que a ATTAC alcançou notoriedade na imprensa internacional. Considerada uma das principais organizadoras da manifestação, a Associação se estendeu pela Europa. Em 2005 a ATTAC estava presente em 50 países, só na França eram 30 mil membros distribuídos em 215 comitês locais.

Vale a pena notar que o apelo de Ramonet e a criação da associação ocorreram em plena crise dos mercados asiáticos. Uma crise que não era apenas uma referência distante para a maioria da população francesa. De acordo com Chauvel (2002), a partir dos anos de 1970 o crescimento econômico na França parou. Enquanto as décadas anteriores traziam os benefícios do período denominado "Trinta Gloriosos" (1945-1975), as décadas posteriores encerravam as vicissitudes do desemprego, da precarização do trabalho, do aumento com gastos em moradia e alimentação, entre outros.

A França passou por três grandes ondas de privatizações. A primeira entre 1986 a 1988 com Jacques Chirac consistiu essencialmente na privatização de indústrias e instituições financeiras. A segunda, entre 1993 a 1997, sob o governo de Édouard Balladur deu continuidade ao processo precedente, intensificando-0. Aqui 0 setor financeiro francês, antes estatizado, foi inteiramente privatizado. $\mathrm{Na}$ terceira grande fase das privatizações, entre 1997 a 2002, com Jospin, o alvo principal foi o setor de serviços, como os Correios. Esse terceiro período é considerado o mais importante em termos de receitas obtidas através das privatizações de empresas públicas. Durante esses três anos foram cerca de 3 mil empresas e mais 1 milhão de trabalhadores transferidos do setor público para o privado. Mas não parou aí. Em 2004, o setor de comunicação francês sofreu seu maior golpe, a privatização da France Télécom. Os efeitos das privatizações que não pararam podem ser sentidos ainda hoje. Recentemente a direção da Télécom teve que lidar com o suicídio de 25 funcionários e mais 15 tentativas. Entre 2008 e 2009 foram várias jornadas de protestos e paralisações em resposta às reformas na saúde e na educação.

Este esboço de um quadro mais complexo e ainda inacabado ajuda a entender o rápido crescimento da ATTAC. A implantação de políticas neoliberais 
e o desmantelamento do Estado providência provocaram mudanças na situação profissional e no cenário político e ideológico da sociedade européia. De modo que as privatizações das indústrias e dos serviços públicos, bem como as reformas dos sistemas de saúde e de educação tiveram impactos sobre a estrutura de classes francesa, que havia sido reorganizada no fim da Segunda Guerra sob o Estado de bem-estar social. De acordo com dados da própria OCDE (Organização para a Cooperação e Desenvolvimento Econômico), a Europa representou mais da metade dos valores privatizados no mundo. Uma rápida olhada para as organizações que compõem a ATTAC evidencia que a queda das condições de vida de um grupo social identificado com as classes médias, particularmente daquelas provenientes do setor público, não está dissociada do processo de criação da associação, nem tampouco das agitações sociais e políticas as quais a França e, num sentido mais geral, a Europa têm passado. Entre algumas das organizações presentes na ATTAC encontram-se: sindicato dos professores; dos médicos; dos bancários; dos engenheiros e técnicos, dos estudantes, dentre outros.

0 grupo nela reunido defende, além da taxa Tobin, o controle mais estreito dos mercados financeiros; a reforma da OMC e das instituições financeiras internacionais (Banco Mundial, FMI); a estatização dos bens comuns, tidos como fundamentais (água, alimentação, informação, educação e saúde); a manutenção do sistema de proteção social e o fim dos fundos de pensão privados.

No entanto, o que realmente destacou internacionalmente os attacantes foi a campanha pela taxa Tobin - tributação que seria arrecadada essencialmente entre os países industrializados, onde estão localizadas as grandes praças financeiras. Essa taxa poderia ser utilizada, segundo seus militantes, no desenvolvimento de projetos sociais que amenizassem a desigualdade (ATTAC, 2002). A proposta tem seus críticos inclusive entre a esquerda, para os quais ela seria reformista. 0 próprio François Chesnais (1999, p.10), membro do comitê científico da associação afirma: "levando-se em conta a modicidade de sua alíquota (...), o tributo Tobin representa um golpe bem menor à mundialização financeira do que, por exemplo, uma medida como o restabelecimento do controle sobre os movimentos de capitais". Por isso, para o autor citado, o objetivo da campanha é primordialmente seu aspecto educativo - 0 que se busca através da campanha pela tributação é afirmar a necessidade de destruir o capital financeiro e de estabelecer uma regulamentação pública internacional (CHESNAIS, 1999). Assim também, para a plataforma da ATTAC (2002, p.105), esse dispositivo se insere dentro de uma perspectiva nitidamente antiespeculativa: "ele alimentaria 
lógicas de resistência, restituiria margens de manobra aos cidadãos e aos Estados e, sobretudo, significaria que a política recupera a prioridade".

A leitura dos textos políticos da associação, bem como das análises apresentadas pelo seu conselho científico nos mostra que questões como poder, Estado e política são peças chaves na compreensão do seu projeto, ao mesmo tempo em que são fontes das suas maiores contradições e debates internos. A interpretação do quadro político, apresentada logo abaixo é uma constante nos documentos da associação. Vejamos:

A mundialização do capital financeiro coloca os povos em estado de insegurança generalizado. Ela ignora e rebaixa as nações e seus Estados, enquanto lugares pertinentes de exercício da democracia e garantia do bem comum [...].

A mundialização financeira tem, aliás, criado seu próprio Estado. Um Estado supranacional, dispondo de seus aparelhos, de suas redes de influência e de seus meios de ação próprios. Trata-se do Fundo Monetário Internacional e do Banco Mundial [...].

Este Estado mundial é um poder sem sociedade, papel exercido pelos mercados financeiros e pelas grandes empresas (...), como consequência, as sociedades realmente existentes, são sociedades sem poder (RAMONET, 1997)?

Segundo tal análise, o Estado perdera a autonomia e as nações a sua soberania, estando todos à mercê dos interesses econômicos dos grandes grupos financeiros. "As instituições democráticas e os Estados soberanos encarregados do interesse geral ${ }^{8 "}$ foram, com 0 neoliberalismo, substituídos por uma "lógica estritamente especulativa" (ATTAC, 2002). É urgente criar "novos instrumentos de regulação e controle, no plano nacional, europeu e internacional" (ATTAC, 1998).

Esses novos instrumentos de regulação têm, segundo a plataforma da associação, o objetivo último de "reconquistar os espaços perdidos pela democracia em proveito da esfera financeira". Trata-se, nas palavras da ATTAC (1998), "de nos apropriarmos juntos novamente do futuro do nosso mundo!”. Frequentemente citada, essa frase expressa claramente que a fase neoliberal representa mais do que déficits no campo econômico, representa perdas no poder de decisão, isto é, déficits no campo político.

\footnotetext{
${ }^{7}$ Grifos nossos.

${ }^{8}$ Grifos nossos.
} 


\section{OS PIQUETEROS E A MOBILIZAÇÃO DOS DESEMPREGADOS}

Entre os movimentos de resistência ao neoliberalismo destaca-se a formação dos movimentos de desempregados argentinos, também identificados como piqueteros. Embora a mobilização dessa parcela dos trabalhadores não seja um fenômeno específico da atual conjuntura, tendo sido verificada em outros contextos históricos e em outros países (como França, Alemanha, Estados Unidos), a constituição desse movimento social na Argentina despertou a atenção de todo 0 mundo pela sua expansão e pela sua importância no plano da ação coletiva. Não poderia ser diferente. 0 surgimento de uma luta de desempregados, dentre os quais muitos com experiência de militância nos movimentos populares ou sindical, se contrapôs às imagens de passividade e desmobilização associadas a eles. Imagem que não refletia o que se viu nos protestos realizados no auge da trajetória do movimento: a presença de centenas ou até milhares de pessoas marchando ou bloqueando estradas.

0 surgimento dos piqueteros insere-se em um período de retomada e intensificação das lutas sociais na Argentina, no qual eram visíveis os impactos da consolidação da política neoliberal pelo governo de Carlos Menem. Este, ao assumir a Presidência da República em julho de 1989, após o governo de Raúl Alfonsín 9 , deu continuidade à aplicação do receituário neoliberal, divulgado neste momento como a via de acesso para o crescimento econômico, o fim das altas taxas de inflação e para a melhoria das condições de vida ${ }^{10}$. Idéia incorporada também por outros países e concretizada na implantação dos princípios neoliberais, cujo cumprimento tornou-se uma exigência do Fundo Monetário Internacional (FMI) e do Banco Mundial aos países periféricos para obtenção de empréstimos.

Sem dúvida, a mobilização dos desempregados representou uma das respostas de ação coletiva constituída frente à diminuição do emprego e à

\footnotetext{
${ }^{9}$ A eleição do candidato da União Cívica Radical (UCR), Raúl Alfonsín, em dezembro de 1983, marcou o início do regime democrático na Argentina, após o fim da ditadura militar que teve início com o golpe de 1976. Com a vitória do radicalista Alfonsín com 51,7\% dos votos, era a primeira vez que os radicais derrotavam os peronistas (abrigados sob a sigla do Partido Justicialista) em eleições livres, alterando a 'lei de ferro' da política argentina, segundo a qual, o peronismo era imbatível neste tipo de eleição (TORRE, 2004; FAUSTO \& DEVOTO, 2004). Apesar das expectativas de renovação política e econômica existente neste período, a crise econômica que perdurou durante o governo radicalista, em especial, a hiperinflação, resultou no retorno do peronismo com a vitória de Carlos Menem nas eleições de maio de 1989 (SVAMPA, 2005).

${ }^{10}$ A implantação do neoliberalismo na Argentina iniciou-se durante o regime militar, mas consolidou-se na década de 1990 com a aplicação de várias reformas estruturais.
} 
necessidade de lutar por garantias mínimas de sobrevivência para os trabalhadores demitidos. Se em seu movimento de redefinição das relações de dominação o capital procurou ampliar ainda mais o seu domínio sobre o conjunto dos trabalhadores, tendo como um dos instrumentos dessa ampliação o aumento do desemprego, na Argentina essa orientação foi seguida à risca, pois a destruição massiva de inúmeros postos de trabalho parece ter sido acompanhada por uma tentativa de aniquilar a força dos movimentos sociais.

Uma das evidências dessa tentativa foi a aplicação das reformas estruturais, entre as quais se destacam a flexibilização do mercado de trabalho e a Reforma do Estado. A primeira, desenvolvida em diferentes etapas, teve o seu marco com a aprovação, em 1991, da Lei Nacional de Emprego (n. 24.013), que estabeleceu: a flexibilização do contrato de trabalho formal; a redução das contribuições patronais à seguridade social; a aplicação do seguro desemprego para apenas alguns setores do mercado formal; a criação de novas modalidades de contratação que facilitassem o contrato por tempo determinado e a demissão - por exemplo, pela isenção do pagamento total ou parcial de contribuições à previdência social e de direitos indenizadores (GIOSA ZUAZUA, 2000; GALVÃO \& ZARPELON, 2006). Por meio destas novas normas, o chamado "custo trabalho" reduziu nos anos de 1990 em torno de 62\%, difundiram-se formas de contratação baseadas na prestação de serviços e na terceirização, como também cresceram ao longo da década os empregos não registrados e o subemprego.

Enquanto a Reforma do Estado autorizou a privatização das empresas estatais, delegou plenos poderes ao Presidente na condução das privatizações e na adoção de medidas cabíveis ao Legislativo, transferiu para as províncias e municípios a administração das áreas da saúde, segurança e educação - exceto o ensino superior (GRASSI, 2003; SVAMPA, 2005; FAUSTO \& DEVOTO, 2004). A rápida aprovação dessa reforma - um mês após Carlos Menem ter assumido a Presidência - mostra a urgência de pôr em andamento as reformas estruturais e a estratégia de impedir o debate sobre tais medidas.

A privatização merece aqui uma análise mais detida. Ela ocorreu em duas etapas: a primeira estende-se até 1991, quando são vendidas as empresas Entel (telefônica) e Aerolíneas Argentinas (transporte aéreo); a segunda etapa foi mais intensa e envolveu um número maior de empresas e serviços - como energia, gás, água, correios, empresas petroleiras e siderúrgicas, a rede de metrô, transporte marítimo e ferroviário e etc. (SVAMPA, 2005). 
0 número de empregados das sete empresas públicas mais importantes que foram privatizadas diminuiu drasticamente. Dos 243.354 mil funcionários públicos existentes em 1985, restaram apenas 75.770, em 1998, o que equivale a uma redução de quase $70 \%$ da força de trabalho (SVAMPA, 2005). Nesse processo é ilustrativo o caso da empresa petroleira Yaciamientos Petrolíferos Fiscales (YPF). Em 1991 a YPF empregava 51.000 mil pessoas, ao ser privatizada este número caiu para 5.600, ou seja, praticamente 90\% dos funcionários (45.400) perderam seus postos de trabalho. 0 fato de ela ter sido a empresa com um dos salários mais altos do setor estatal e composta por trabalhadores com uma forte experiência sindical (ALMEYRA, 2005), nos dá pistas para entender quão avassaladora foi a sua privatização $0^{11}$ e a dimensão política do desemprego.

Para muitos empregados públicos, cuja trajetória profissional e familiar havia sido estruturada em torno da YPF, era a primeira vez que vivenciavam a experiência do desemprego. Mas para o conjunto, a demissão representava 0 fim de uma carreira estável e da garantia de direitos e proteções trabalhistas que vinham sendo, cada vez mais, alvos de ataque. As pressões psicológicas e a ameaça da perda do emprego começaram já em 1987, com a entrada das primeiras empresas privadas no interior da YPF (KOROL, 2005) e, posteriormente, com a reestruturação promovida pelo governo com a finalidade de tornar a empresa mais enxuta e atraente para o capital privado.

0 processo que culminou na privatização da YPF foi marcado por tensões e conflitos. Somado a isso, houve ainda a rejeição da população às paralisações e marchas encabeçadas pelo movimento sindical nos primeiros anos de 1990, consideradas abusivas para uma categoria que contava com salários altos. Posteriormente o apoio popular se efetivou, inclusive quando os impactos da privatização haviam atingido toda a dinâmica da economia local das regiões petroleiras.

0 germe da organização dos desempregados encontra-se, então, nas lutas realizadas a partir de 1996 nas cidades petroleiras localizadas no interior do país, especialmente, nas províncias de Salta e Neuquém. Para exemplificar, em Tartagal e General Mosconi (municípios de Salta), o desemprego atingiu em torno de 80\% da População Economicamente Ativa (PEA) (MACHADO,

${ }^{11}$ A venda da siderúrgica Somisa (Sociedad Mixta Siderurgia Argentina) é um exemplo semelhante. Do total de 12 mil empregados, 50\% ficaram desempregados entre 1991-1992 (SVAMPA, 2005). 
2004). Contando com o apoio sindical e popular, os ex-funcionários públicos foram, então, os protagonistas das primeiras mobilizações que originaram os movimentos piqueteros. A experiência de militância sindical e a tradição política desses trabalhadores contribuíram com a conformação de uma ação coletiva que se difundiu progressivamente para outras províncias, sobretudo em Buenos Aires. Nesse sentido, cabe enfatizar a composição inicial dessas mobilizações e a militância sindical como um traço importante do perfil desses desempregados.

À medida que a mobilização ganhou novos espaços, ela adquiriu também novos contornos relacionados ao histórico de luta dessas regiões, ao perfil e à trajetória da população desempregada. Na Grande Buenos Aires, considerada 0 principal pólo industrial do país e onde os piqueteros mais se desenvolveram, os impactos das reformas estruturais poderiam ser observados também na acentuada diminuição de postos de trabalho industriais causada pela desindustrialização. Dados da região metropolitana de Buenos Aires para o período de 1993 e 2001 mostram que o emprego industrial reduziu 31\%, sendo que nas manufaturas essa redução correspondeu a 23\%. Com isso, o desemprego aberto registrado no país em 9\% no ano de 1993, atingiu 20\% em 2001 (GIOSA ZUAZÚA, 2005). Esse processo foi acompanhado pela redução do salário real, pelo aumento da pobreza e do número de empregos desprovidos de proteção trabalhista.

$\mathrm{Na}$ Grande Buenos Aires, os movimentos de desempregados apresentaram, portanto, uma composição social muito mais heterogênea. Trabalhadores originários da indústria, da construção civil, dos serviços e, sobretudo, mulheres, donas-de-casa, constituíram inicialmente as organizações piqueteras formadas nessa região. Enquanto uma parte dos desempregados era herdeira de uma militância sindical, uma parcela das mulheres envolvidas não tinha como referência uma participação política em sindicatos ou partidos, contudo, além do envolvimento nas atividades realizadas no interior das organizações e nas formas de protesto, coube a elas, muitas vezes, a mediação e a aproximação entre a organização e seus maridos desempregados. 0 engajamento feminino foi motivado pela necessidade emergencial de lutar pela sobrevivência, ameaçada pela falta de trabalho e renda. 0 protagonismo feminino evidenciou-se inicialmente à frente das marchas e, cada vez mais, na organização dos "restaurantes populares" (comedores), das hortas comunitárias e das atividades vinculadas ao bairro.

Paralela à luta por emprego, a reivindicação principal e imediata dos movimentos piqueteros consistiu na luta pelos planos sociais, um benefício 
destinado aos desempregados ${ }^{12}$. Enquadrados nos marcos de uma política focalizada, os planos sociais representavam a solução emergencial para o enorme contingente de desempregados sem nenhuma renda ou sem o direito a um segurodesemprego, já que este não só havia sido criado recentemente como fora destinado apenas para alguns setores.

Esse objetivo imediato não elimina o caráter contestador dos movimentos ao neoliberalismo, nem impediu que algumas organizações piqueteras tentassem pôr em prática uma luta política; apesar dos seus limites, a luta pela sobrevivência evidencia de certo modo a radicalidade da implantação das políticas neoliberais na Argentina, onde houve uma concentração da riqueza e o crescimento das camadas mais pobres dos setores populares ${ }^{13}$. Tais políticas respondiam diretamente a interesses de classes, para os quais o desemprego representava uma forma de enfraquecer a capacidade de resistência dos trabalhadores e a possibilidade de estabelecer uma nova correlação de forças.

Por isso, a emergência dos piqueteros teve o papel de pôr em causa 0 neoliberalismo e de evidenciar a necessidade de organizar os desempregados enquanto parte da classe trabalhadora; no entanto, eles estiveram também expostos a contradições internas e a cooptações por parte do Estado.

Os movimentos piqueteros não estiveram isentos de diferenças políticoideológicas. As diversas organizações que os compõem distinguiram-se entre si, assim como as orientações políticas, as alianças e os objetivos adotados por cada uma delas. Se, a despeito das diferenças, foi possível construir inicialmente uma estratégia de cooperação entre as distintas correntes e um repertório de ações

\footnotetext{
${ }^{12}$ Este benefício foi assegurado com a criação dos programas de Emergencia Laboral "Trabajar" (1996-2001), que destinava 200 pesos mensais (50 dólares) durante 6 meses aos beneficiários, exigindo em troca a contraprestação de serviços. Em 2002 foi criado o Programa Jefas y Jefes de Hogar que, embora tenha ampliado a cobertura, diminuiu o valor do benefício para 150 pesos e manteve também o critério da contraprestação dos beneficiários, por um período de 4 horas diárias, em atividades de capacitação, comunitárias, entre outras.

${ }^{13}$ Exemplifica esse aumento da pobreza a intensificação do número de "cartoneros" - catadores de lixo -, que entre 2001 e 2002, passou de 25 mil para 40 mil na cidade de Buenos Aires. Segundo dados publicados pelo jornal Clarín, os cartoneros são compostos em sua grande maioria por exgarçons, ex-metalúrgicos, ex-empregadas domésticas, ex-sapateiros, entre outros trabalhadores, cujas trajetórias de vida percorreram as seguintes fases: $1^{\circ}$ trabalhador relativamente formal; $2^{\circ}$ desempregado; $3^{\circ}$ carências materiais, familiares e psicológicas; $4^{\circ}$ imersão na atividade cartonera. Ver "Los ejércitos de la noche. La Argentina de cartón". Clarín, 27/10/2002. Disponível em: http:// www.clarin.com/suplementos/zona/2002/10/27/z-00215.htm
} 
em comum, como por exemplo os piquetes, (SVAMPA, 2008), posteriormente as divergências se acirraram, demarcando e redefinindo o espaço ocupado pelas organizações na arena política: de um lado, as integradas e dispostas a conciliar com o governo e, de outro, as críticas e opositoras.

Somaram-se ao acirramento desse conflito e à dificuldade de construir um projeto político comum, a desqualificação dos movimentos por parte da mídia e a criminalização dos militantes das organizações mais mobilizadas. A quantidade de processos judiciais abertos pelo governo contra inúmeros militantes demonstra como o uso da repressão foi utilizado como forma de desmobilizar ou eliminar as ações coletivas que recusam a ordem estabelecida ${ }^{14}$.

Mas a combinação entre cooptação e difusão de uma política focalizada talvez tenha sido a estratégia de desmobilização de maior impacto para os movimentos. A cooptação correspondeu à forma encontrada pelo governo de Néstor Kirchner (2003-2007) para "disciplinar" as organizações piqueteras e isolar aquelas mais resistentes a esse tipo de controle (SVAMPA, 2008). Em troca do arrefecimento dos protestos, o governo buscou delimitar as ações dos movimentos à obtenção/disputa de benefícios (como os planos sociais), por meio da aplicação das políticas focalizadas. Tratou-se, então, de um duplo processo, cujos efeitos políticos não se limitaram à neutralização dos conflitos e ao enfraquecimento da capacidade organizativa, pois tenderam a fortalecer também a orientação neoliberal seguida pelo governo.

Os desafios colocados aos movimentos piqueteros frente a esse cenário foram e continuam sendo inúmeros, contudo, um merece ser destacado: como construir uma unidade política a fim de frear e impedir a continuidade da ofensiva neoliberal que, apesar das ações de resistência surgidas e intensificadas no país, mantém o seu vigor?

\section{Considerações FINAIS}

Tal como vimos até aqui, tanto nos países centrais como nos países periféricos, as políticas neoliberais e 0 processo de reestruturação produtiva

\footnotetext{
${ }^{14}$ Conforme dados apresentados por Horácio Meguira, diretor jurídico da CTA, em 2007 havia 3.000 militantes piqueteros sendo processados no país por "perturbação à ordem" ou "danos ao patrimônio", o que revela "(...) uma criminalização sistemática das atitudes desses movimentos". Ver "Verba de Kirchner dissolve 'piqueteros"', Folha de S. Paulo, 26/10/2007.
} 
provocaram impactos sobre as relações de trabalho e sobre a estrutura de classes. De um lado, temos o desemprego de longa duração que levou uma parcela da população para a informalidade e para os trabalhos temporários, de outro temos um aumento cada vez maior de pessoas "qualificadas" nos trabalhos terceirizados e submetidos a relações de trabalho instáveis e precárias. As condições de vida e de trabalho dos grupos sociais reunidos no altermundialismo e nos piqueteros foram duramente afetadas. Embora se trate de grupos distintos, que sofreram de maneiras diferentes as transformações recentes do capitalismo, cujos impactos repercutiram inclusive de modo diferenciado de acordo com o país, com a sua tradição de luta, com a sua história política, entre outros elementos, o fato é que ambos buscam configurar alternativas ao neoliberalismo.

Em oposição às proposições elaboradas por autores como Melucci (1989) e Touraine (1989) sobre a nova orientação dos movimentos sociais para questões de ordem cultural e não mais econômicas na chamada "sociedade pós-industrial", para nós, a trajetória destes dois movimentos explicita 0 contrário: protestam contra mudanças de base material que atingiram a estrutura social e refletem a nova configuração da luta de classes.

Enessa conclusão não háespaços parasimplismos. Certamente a expansãoe a radicalização da lógica capitalista através do processo de reestruturação produtiva e da implantação da receita neoliberal impactaram negativamente diversos grupos sociais em seus diferentes contextos sócio-históricos. Se num processo mais amplo, isto é, do ponto de vista estrutural, essas transformações aproximaram trabalhadores brancos europeus de trabalhadores rurais (por vezes indígenas) da América do Sul e todos estes se tornaram sensíveis, não apenas por solidariedade e humanismo, à privatização de terras comunitárias, ao endividamento dos países pobres e ao processo imigratório para e na Europa, é necessário constatar que a construção de uma solidariedade política global tem também seu tempo e sua lógica própria. As diferenças de língua, território, costumes, gênero não se apagam dentro das classes, ao contrário, demarcam modos, níveis e intensidades variadas de exploração. É esse tipo de contribuição que o desenvolvimento deste trabalho conjunto pode configurar. A análise comparativa destes dois movimentos além de evidenciar semelhanças e diferenças organizacionais, pode esclarecer algumas questões, tais quais: 1) na luta destes movimentos contra 0 neoliberalismo aparecem propostas anticapitalistas? 2) em que medida as diferentes formas de atuação e reivindicação entre altermundialistas e piqueteros estão associadas às 
bases sociais de cada um deles? 3) quais as implicações políticas no plano da ação coletiva de ser trabalhador num país de centro e outro da periferia do capitalismo?

Essas e outras questões merecem uma atenção mais detida, podendo ser tratadas com mais acuidade no desenvolvimento posterior deste trabalho conjunto. Para os limites deste texto, no entanto, procuramos esboçar apenas algumas reflexões mais gerais.

\section{REFERÊNCIAS}

ALMEYRA, Guillermo. La protesta social en Argentina (1990-2004). Buenos Aires: Ediciones Continente, 2004.

AMORIM, Henrique José Domiciano. Teoria social e reducionismo analítico: para uma crítica ao debate sobre a centralidade do trabalho. Caxias do Sul: Educs, 2006.

ANDERSON, Perry. Balanço do neoliberalismo. In: SADER, Emir; GENTILI, Pablo. (orgs.). Pós-neoliberalismo: as políticas sociais e o Estado democrático. Rio de Janeiro: Paz e Terra, 1995.

ARCE0, Enrique; BASUALDO, Eduardo. Los cambios de los sectores dominantes en América Latina bajo el neoliberalismo. In: ARCEO, Enrique; BASUALDO, Eduardo (orgs.). Neoliberalismo y sectores dominantes: tendencias globales y experiencias nacionales. Buenos Aires: CLACSO, 2006.

ATTAC. Statuts de l'association 03/06/1998. In http://www.france.attac.org/spip. php?article604

. Tout sur Attac. Paris: Éditions Mille et Une Nuits, 2002.

BATISTA JR., Paulo Nogueira. Argentina: uma crise paradigmática. Estudos Avançados, vol 16, n. 44, São Paulo, 2002, p.83-96.

BOITO JR, Armando. Política neoliberal e sindicalismo no Brasil. São Paulo: Xamã, 1999 .

CARRERA, Nicolás Iñigo; COTARELO, Maria Célia. Argentina, diciembre de 2001: Hito en el proceso de luchas populares. In: SEOANE, José. (org.). Movimientos sociales y conflicto en América Latina. Buenos Aires: Clacso, 2004.

CHAUVEL, Louis. Classes e gerações: a insuficiência das hipóteses da teoria do fim das classes sociais. Crítica Marxista, n.15, São Paulo, 2002, p.57-70. 
CHESNAIS, François. Tobin or not Tobin ? Porque tributar o capital financeiro internacional em apoio aos cidadãos. São Paulo: UNESP e ATTAC, 1999.

DUMÉNIL, Gerard; LEVY, Dominique. 0 imperialismo na era neoliberal. Crítica Marxista, n. 18, Rio de Janeiro, 2004, p.11-36.

. Une théorie marxiste du néolibéralisme. Acutel Marx: Fin du néolibéralisme? N. 40, Paris, 2006, p.24-38.

EVANGELISTA, Fernando. Gênova 2001: o recado da juventude. Caros Amigos, ano V, n.53, agosto, 2001.

FAUSTO, Boris; DEVOTO, Fernando J. Brasil e Argentina: um ensaio de história comparada (1850-2002). São Paulo: Editora 34, 2004.

FAVAR0, Orietta. Protesta social y representación en las provincias argentines: Neuquen en la última década. In: SEOANE, José. (org.) Movimientos sociales y conflicto en América Latina. Buenos Aires: Clacso, 2004.

GALVÃO, Andréia; ZARPELON, Sandra. A flexibilização trabalhista na Argentina. 2006. (mimeo).

GIOSA ZUAZUA, Noemí Beatriz. Dinámica del mercado de empleo y regulación laboral en Argentina - Antecedentes y transformaciones de los 90s. ¿Hacia a dónde vamos? Paper presentado en The Argentina Observatory, dic/2005.

. Neoliberalismo, reestruturação produtiva e emprego na Argentina nos anos 90. Dissertação de Mestrado, Economia, Universidade Estadual de Campinas, 2000.

GRASSI, Estela. Política, cultura y sociedad: la experiencia neoliberal en la Argentina. In: LINDENBOIN, Javier; DANANI, Claudia. (orgs.) Entre el trabajo y la politica: las reformas de las politicas sociales argentinas en perspectiva comparada. Buenos Aires: Biblos, 2003.

IBASE. Fórum Social Mundial. Disponível em: http://www.ibase.org.br/modules. php?name $=$ Conteudo\&pid=1070. Acesso em 15/07/2007.

KLACHKO, Paula. Objetivos de la protesta de cinco organizaciones de desocupados: Primer semestre 2002 - primer semestre 2004. PIMSA - Publicación del Programa de Investigación sobre el Movimiento de la Sociedad Argentina, año IX, n. 9, Buenos Aires, 2005, p. 160-197.

KOROL, Claudia (org.). Cortando las rutas del petróleo. Buenos Aires: Ediciones Madres de Plaza de Mayo, 2005. 
LEITE, José Correa. As invenções da política: sobre a existência da política e suas transformações. Tese de doutorado, Ciências Sociais, Pontifícia Universidade Católica de São Paulo, 2005.

MACHADO, Eliel Ribeiro. Mal-estar da democracia no Brasil e na Argentina nos anos 90: lutas sociais na contramão do neoliberalismo. Tese de doutorado, Ciências Sociais, Pontifícia Universidade Católica de São Paulo, 2004.

MORAES, Reginaldo. Neoliberalismo. De onde vem e para onde vai? São Paulo: Senac, 2001.

MELUCCI, Alberto. Um objetivo para os movimentos sociais? Lua Nova, n.17, São Paulo, 1989, p.49-66.

PALOMINO, Héctor; RAJHER, Gustavo; POLIAGHI, Leticia; LASCANO; Inés. A política e o político nos movimentos sociais na Argentina. In: DAGNINO, Evelina; OLIVERA, Alberto J.; PANFICHI, Aldo. A disputa pela construção democrática na América Latina. São Paulo: Paz e Terra, 2006.

PAUTASSI, LAURA; ROSSI, Julieta; CAMPOS, Luis. Plan Jefes y Jefas: ¿Derecho social o beneficio sin derechos? Buenos Aires: Centro de Estudios Legales y Sociales (CELS), 2004.

RAMONET, Ignacio. Désarmer les marches. Le monde diplomatique, 01/12/1997.

SANTOS, Boaventura de Sousa. O Fórum Social Mundial - manual de uso. São Paulo: Cortez, 2005.

SVAMPA, Maristella. Argentina: una cartografía de las resistencias (2003-2008). Entre las luchas por la inclusión y las discusiones sobre el modelo de desarrollo. Osal, Buenos Aires, año IX, n. 24, octubre, 2008, p. 17-49.

. La Sociedad Excluyente. La Argentina bajo el signo del neoliberalismo. Buenos Aires: Taurus, 2005.

SVAMPA, Maristella; Pereyra, Sebastián. Entre la ruta y el barrio. La experiencia de las organizaciones piqueteras. Buenos Aires: Biblos, 2003.

TORRE, Juan Carlos. A crise da representação partidária na Argentina. In: Brasil e Argentina hoje: política e economia. Bauru: Edusc, 2004, p. 153-186.

TOURAINE, Alain. Os novos conflitos sociais - para evitar mal-entendidos. Lua Nova, n. 17, São Paulo, 1989, p.5-18. 